\title{
Effect of Different Dosages of Dexamethasone Therapy on Lung Function and Inflammation in an Early Phase of Acute Respiratory Distress Syndrome Model
}

\author{
P. MIKOLKA ${ }^{1,2}$, P. KOSUTOVA ${ }^{1,2}$, M. KOLOMAZNIK ${ }^{1,2}$, J. TOPERCEROVA $^{2}$, \\ J. KOPINCOVA ${ }^{2}$, A. CALKOVSKA ${ }^{1,2}$, D. MOKRA ${ }^{1,2}$
}

${ }^{1}$ Biomedical Center Martin, Jessenius Faculty of Medicine in Martin, Comenius University in Bratislava, Martin, Slovak Republic, ${ }^{2}$ Department of Physiology, Jessenius Faculty of Medicine in Martin, Comenius University in Bratislava, Martin, Slovak Republic

Received March 21, 2019

Accepted October 27, 2019

\section{Summary}

Inflammation associated with acute respiratory distress syndrome (ARDS) can damage the alveolar epithelium and surfactant and worsen the respiratory failure. Glucocorticoids (GC) appear to be a rational therapeutic approach, but the effect is still unclear, especially for early administration and low-dose. In this study we compared two low doses of dexamethasone in early phase of surfactant-depleted model of acute respiratory distress syndrome (ARDS). In the study, lung-lavaged New Zealand rabbits with respiratory failure $\left(\mathrm{PaO}_{2}<26.7 \mathrm{kPa}\right.$ in $\left.\mathrm{FiO}_{2} 1.0\right)$ were treated with intravenous dexamethasone (DEX): $0.5 \mathrm{mg} / \mathrm{kg}$ (DEX-0.5) and $1.0 \mathrm{mg} / \mathrm{kg}$ (DEX-1.0), or were untreated (ARDS). Animals without ARDS served as controls. Respiratory parameters, lung edema, leukocyte shifts, markers of inflammation and oxidative damage in the plasma and lung were evaluated. Both doses of DEX improved the lung function vs. untreated animals. DEX-1.0 had faster onset with significant improvement in gas exchange and ventilation efficiency vs. DEX-0.5. DEX-1.0 showed a trend to reduce lung neutrophils, local oxidative damage, and levels of TNFa, IL-6, IL-8 more effectively than DEX-0.5 vs. ARDS group. Both dosages of dexamethasone significantly improved the lung function and suppressed inflammation in early phase ARDS, while some additional enhancement was observed for higher dose $(1 \mathrm{mg} / \mathrm{kg}$ ) of DEX.

\section{Key words}

Acute respiratory distress syndrome • Glucocorticoids • Dexamethasone $\bullet$ Lung function $\bullet$ Inflammation

\section{Corresponding author}

D. Mokra, Department of Physiology and Biomedical Center Martin, Jessenius Faculty of Medicine in Martin, Comenius University in Bratislava, Mala Hora 4C, SK-03601 Martin, Slovak Republic. E-mail: daniela.mokra@uniba.sk

\section{Introduction}

Acute respiratory distress syndrome (ARDS) is still a serious life-threatening condition. Despite the favorable impact of the lung-protective ventilation strategy demonstrated in the ARDSnet study, the incidence and overall mortality of ARDS have not changed substantially (Villar et al. 2014). ARDS involves acute diffuse, inflammatory lung injury leading to increased pulmonary vascular permeability, and loss of aerated lung tissue. The clinical hallmarks are hypoxemia and bilateral radiographic opacities, associated with increased physiological dead space and decreased lung compliance (Ranieri et al. 2012). Increase in activated neutrophils is a critical final pathway of the lung injury during ARDS resulting in deterioration of alveolarcapillary membrane and alveolar epithelium by the release of toxic mediators (Zemans et al. 2009, Matthay and Zemans 2011). The epithelial injury leads to surfactant alterations and together with edema formation, ventilation-perfusion mismatch and inflammation reduces the lung compliance and hypoxemia and further deteriorates the lung function (Verbrugge et al. 1997, Pierrakos et al. 2012). 
Therapeutic protocol for ARDS is almost based on the lung-protective ventilation and fluid-conservative management. A large number of pharmacologic therapies, such as glucocorticoids (GC), surfactants, inhaled nitric oxide, antioxidants, protease inhibitors, and other anti-inflammatory drugs have been tested in the ARDS treatment, but without clear evidence of positive effect (Cepkova and Matthay 2006). GC have appeared to be perspective due to their multiple anti-inflammatory, anti-edematous and pulmonary vasodilator actions (Czock et al. 2005, Coutinho and Chapman 2011), particularly in systemic administration (Peter et al. 2008). Despite presumed therapeutic potential, use of GC in patients with ARDS led to controversial results (Meduri et al. 2007, Tang et al. 2009, Ruan et al. 2014). However, administration of dexamethasone in our previous experimental studies was of benefit and become the basis for this study. Dexamethasone positively influenced the lung functions and attenuated inflammation (Mokra et al. 2007, Kosutova et al. 2016). There is also increasing evidence that lower dose of GC administered earlier after developing ARDS could be beneficial (Meduri et al. 2007, Narute et al. 2017, Yang et al. 2017). However, due to heterogeneous nature of ARDS the appropriate dosing regimens, timing and duration of GC therapy as well as reasonability for their use are still discussed.

We hypothesized that low dose of dexamethasone in ARDS would decrease the inflammatory response and thereby alleviate the lung injury. Therefore, the purpose of this study was to determine the effects of two different low bolus doses of dexamethasone administered systemically on the lung function and the leukocyte and inflammatory profiles in an acute phase of experimental ARDS.

\section{Methods}

\section{Animal instrumentation}

This study was approved by the National Veterinary Board of Slovakia and the local Ethical Committee of Jessenius Faculty of Medicine in Martin, Comenius University in Bratislava. Adult New Zealand white rabbits of both genders with a body weight (b.w.) of $2.8 \pm 0.3 \mathrm{~kg}$ were instrumented in accordance with previous study (Kosutova et al. 2017). After initial anaesthesia with intramuscular tiletamine and zolazepam (15 mg/kg b.w.; Zoletil, Virbac, France) and xylazine ( $5 \mathrm{mg} / \mathrm{kg}$ b.w.; Xylariem, Riemser, Germany), animals were sedated by i.v. infusion of anesthetics (tiletamine and zolazepam, $10 \mathrm{mg} / \mathrm{kg} / \mathrm{h}$ ). Subsequently, the animals were mechanically ventilated (Aura V, Chirana, Slovakia) with positive end-expiratory pressure (PEEP) of $0.5 \mathrm{kPa}$, tidal volume $\left(\mathrm{V}_{\mathrm{T}}\right)<6 \mathrm{ml} / \mathrm{kg}$, time of inspiration (Ti) $50 \%$, respiratory rate (RR) of 40 breaths per minute (bpm), and $\mathrm{FiO}_{2}$ of 1.0 throughout the experiment. Finally, $4 \mathrm{~h}$ after the treatment, the animals were sacrificed by an overdose of anesthetics. Electrocardiographic monitoring using subcutaneous electrodes and invasive arterial pressure monitoring were carried out continuously using multi-channel recorder PowerLab 8/30 (AD Instruments, Germany). Gas exchange and parameters of acid-base balance were measured from arterial blood samples using blood gas analysis (RapidLab TM ${ }^{348}$, Bayer Diagnostics, Germany). Ventilation parameters were measured by in-build sensors and software of ventilator Aura $\mathrm{V}$. The following parameters were calculated: $\mathrm{P} / \mathrm{F}=$ calculated as a ratio between arterial oxygen partial pressure $\left(\mathrm{PaO}_{2}\right)$ and fraction of inspired oxygen $\left(\mathrm{FiO}_{2}\right)$; oxygenation index $(\mathrm{OI})=\left(\right.$ Mean airway pressure $\left.\mathrm{x} \mathrm{FiO}_{2}\right) / \mathrm{PaO}_{2}$; ventilation efficiency index $(\mathrm{VEI})=3800 /[(\mathrm{PIP}-\mathrm{PEEP}) \mathrm{x}$ frequency $\times \mathrm{PaCO}_{2}$ ]; and alveolar-arterial gradient $(\mathrm{AaG})$ $=\left[\mathrm{FiO}_{2}\left(\mathrm{P}_{\mathrm{atm}}-\mathrm{PH}_{2} \mathrm{O}\right)-\mathrm{PaCO}_{2} / 0.8\right]-\mathrm{PaO}_{2}$, where $\mathrm{P}_{\mathrm{atm}}$ is barometric pressure and $\mathrm{PH}_{2} \mathrm{O}$ is pressure of water vapor.

\section{Experimental model of ARDS}

After $15 \mathrm{~min}$ of stabilization period, the respiratory parameters and blood gases were recorded (basal values, BV). According to modified protocol by authors, the lung injury was induced by repetitive lung lavage with a saline $\left(30 \mathrm{ml} / \mathrm{kg}\right.$ b.w., $\left.37^{\circ} \mathrm{C}\right)$ instilled into the endotracheal cannula in the semi-upright right and left lateral positions of the animal and immediately suctioned by a suction device. The lavages were repeated with stabilization periods of $2 \mathrm{~min}$ ventilation in between, until $\mathrm{PaO}_{2}$ in the arterial blood decreased to $<26.7 \mathrm{kPa}$ in $\mathrm{FiO}_{2}$ 1.0 and lung compliance decreased of $<30 \%$ of the initial value in two measurements at 5 and $15 \mathrm{~min}$ after the last lavage, which equals moderate ARDS. At this point the respiratory parameters and blood gases were recorded again (Model). During the lavage protocol animals were ventilated using unchanged settings $\left(\mathrm{V}_{\mathrm{T}}<6 \mathrm{ml} / \mathrm{kg}\right.$, PEEP $0.5 \mathrm{kPa}$, Ti $50 \%$, RR $40 \mathrm{bpm}$ and $\mathrm{FiO}_{2} 1.0$ ).

\section{Treatment protocol}

After the criteria of lung injury were full-filled, the animals were assigned randomly to the following 
three groups ( $\mathrm{n}=7$ for each group): (i) ARDS group, without treatment; (ii) DEX-0.5 group, ARDS with $0.5 \mathrm{mg} / \mathrm{kg}$ dexamethasone i.v.; (iii) DEX-1.0 group, ARDS with $1.0 \mathrm{mg} / \mathrm{kg}$ dexamethasone i.v.; dexamethasone natrium phosphate (Dexamed sol inj, $8 \mathrm{mg} / 2 \mathrm{ml}$, Medopharm, Czech Republic). One group of animals served as healthy, ventilated and non-treated controls (Control, $\mathrm{n}=7$ ). All animals were oxygen-ventilated $\left(\mathrm{V}_{\mathrm{T}}<6 \mathrm{ml} / \mathrm{kg}\right.$, PEEP $0.5 \mathrm{kPa}$, Ti $50 \%$, RR $40 \mathrm{bpm}$ and $\mathrm{FiO}_{2}$ 1.0) for additional $4 \mathrm{~h}$. Post-treatment physiological data such as blood gases, acid-base balance and respiratory parameters were recorded at $30 \mathrm{~min}, 1,2,3$ and $4 \mathrm{~h}$ after the therapy (Th).

Total and differential leukocytes count in arterial blood and $B A L F$

After $4 \mathrm{~h}$ after the treatment and sacrificing the animal, lungs and trachea were excised. The left lung was lavaged with saline (3-times, $10 \mathrm{ml} / \mathrm{kg} \mathrm{b.w.)} \mathrm{to} \mathrm{obtain}$ a bronchoalveolar lavage fluid (BALF). Total leukocyte count was determined microscopically in a counting chamber after staining by Türck. The differential cell counts in the BALF and arterial blood were estimated microscopically after staining by May-Grünwald/GiemsaRomanowski.

\section{Post-mortem analyses}

Levels of cytokines, apoptotic marker and oxidative modifications were determined in plasma and in $10 \%$ (weight/volume) lung homogenate. Oxidative modification was determined using kits: OxiSelect ${ }^{\mathrm{TM}}$ Nitrotyrosine ELISA Kit (Cell Biolabs, Inc., USA) for protein oxidation expressed in 3-nitrotyrosine nanomolar concentration (nM 3NT); OxiSelect $^{\text {TM }}$ TBARS Assay Kit (Cell Biolabs Inc., USA) for lipid oxidation expressed as malondialdehyde in micromolar concentration ( $\mu \mathrm{M}$ MDA). Levels in $\mathrm{pg} / \mathrm{ml}$ of $\mathrm{TNF} \alpha$, IL-6, and IL-8 were quantified using rabbit-specific ELISA kits (Cloud-Clone Corp., USA) and the apoptotic marker caspase-3 using rabbit-specific ELISA kit (Cusabio Biotech Co Ltd, China) according to the manufacturers' instructions.

Strips of the right lung lobe were weighed before and after drying in an oven at $60{ }^{\circ} \mathrm{C}$ for $48 \mathrm{~h}$ to calculate the wet-to-dry (W/D) lung weight ratio, extent of the lung edema. Total protein content in the BALF was determined by Bradford colorimetric method and were expressed in $\mu \mathrm{g} / \mathrm{ml}$.

\section{Statistical analysis}

Analysis of data was performed using statistical software Graph Pad Prism 6.01 (USA). Two-way analysis of variance (ANOVA) with Dunnett's multiple comparison test for dynamic changes parameters and Kruskal-Wallis non-parametric test for groups comparison were used. A $p<0.05$ was considered for statistically significant. The results are presented as mean \pm SEM

\section{Results}

The data from 28 rabbits of both genders were used for the analysis. At the beginning of experiments, there were no significant differences in the entry parameters (body weights, gender rate) and the initial values of respiratory parameters among the all groups (for all $p>0.05$ ). Induction of ARDS affected the lung function parameters compared to the baseline values (time sequence Model vs. BV; $p<0.001$ ), however in the observed time point for Model, there were no significant differences in these parameters between all ARDS groups (ARDS vs. DEX-0.5 vs. DEX-1.0; for all $p>0.05$ ).

\section{Lung function parameters}

Induction of lung injury caused a significant deterioration in the lung function parameters. All observed respiratory parameters $\left(\mathrm{PaO}_{2} / \mathrm{FiO}_{2}, \mathrm{OI}, \mathrm{VEI}\right.$, AaG, MAP, $C_{\text {dyn }}$, Raw) had been severely altered after the lavage compared to the controls (for all $p<0.001$ ) and this trend persisted till the end of the experiment (Fig. 1, Table 1).

Both doses of dexamethasone significantly improved $\mathrm{P} / \mathrm{F}$ ratio, OI and $\mathrm{AaG}$ compared to ARDS, while the higher one (DEX-1.0) showed rapid onset (at $30 \mathrm{~min} \mathrm{Th} p<0.05$ ) and long term effect (at $4 \mathrm{~h} \mathrm{Th}$ $p<0.001$ ) (Fig. 1). Other lung function parameters were also improved after DEX therapy (Table 1). Only DEX-1.0 improved VEI vs. ARDS at 3 and $4 \mathrm{~h}$ Th $(p<0.05)$. Superior effect for DEX-1.0 towards DEX-0.5 was observed in $\mathrm{P} / \mathrm{F}$ ratio and $\mathrm{AaG}$ (DEX-1.0 vs. DEX-0.5, $p<0.05$ ) (Fig. 1A, 1D).

\section{Leukocytes in the blood and cells in the BALF}

In the blood, total leukocytes count in the untreated ARDS animals significantly decreased vs. controls $(p<0.05)$ what reflected a decrease in neutrophils $(p<0.01)$ and monocytes $(p<0.05)$. Both DEX therapies significantly elevated the circulating neutrophils $(p<0.05$ 

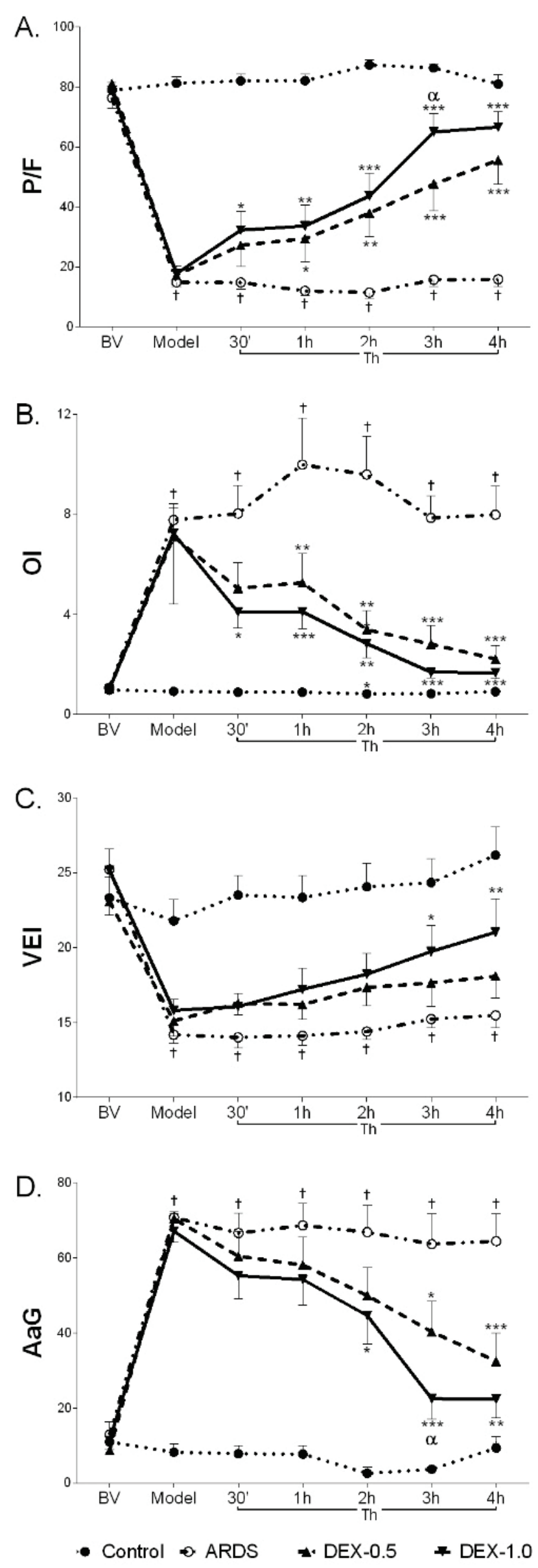

Fig. 1. Respiratory parameters: $(\mathbf{A})$ the ratio of arterial oxygen partial pressure to fraction of inspired oxygen (P/F), (B) oxygenation index (OI), (C) ventilation efficiency index (VEI), (D) alveolar-arterial gradient ( $\mathrm{AaG}$ ) before (basal value, BV) and in ARDS condition (Model) and during $4 \mathrm{~h}$ after the therapy (Th) in Control group, ARDS untreated group, and ARDS groups treated with $0.5 \mathrm{mg} / \mathrm{kg}$ of dexamethasone (DEX-0.5) or $1.0 \mathrm{mg} / \mathrm{kg}$ of dexamethasone (DEX-1.0). Data are presented as means \pm SEM. Statistical comparisons: for ARDS vs. Control ${ }^{+} p<0.001$; for DEX-0.5 \& DEX-1.0 vs. ARDS ${ }^{*} p<0.05,{ }^{* *} p<0.01$, ${ }^{* * *} p<0.001$; and for DEX-1.0 vs. DEX-0.5 ${ }^{\mathrm{a}} p<0.05$.

vs. ARDS), for DEX-1.0 also monocytes $(p<0.05)$. In opposite, percentage of lymphocytes increased in ARDS group ( $p<0.01$ vs. Control) and decreased after the DEX therapies ( $p<0.05$ vs. ARDS group) (Table 2$)$.

Local lung injury was linked with an influx of leukocytes into BALF with increase of total count $(p<0.001)$, neutrophils $(p<0.001)$ and eosinophils $(p<0.05)$ and decrease of monocytes $(p<0.001)$ in the ARDS group vs. Control. Both DEX therapies reduced total leukocytes count, with bigger impact for DEX-1.0 $(p<0.01$ vs. ARDS). Only DEX-1.0 significantly increased monocytes and decreased neutrophils leak into the lung (both $p<0.05$ vs. ARDS group) (Table 2).

Inflammation, apoptosis and oxidation in the plasma and lung tissue

The lung deterioration after the lavage in ARDS group was highlighted by the increase of all observed markers in the plasma and lung vs. Control (Table 3, Fig. 2). In plasma (Table 3), both dexamethasone therapies affected their levels, but only DEX-1.0 significantly reduced TBARS, TNF $\alpha$ and IL-6 (for all $p<0.05$ ). In the lung tissue (Fig. 2), both DEX therapies reduced the levels of TNF $\alpha$, IL-8, Casp-3 and TBARS with higher statistical impact for DEX-1.0 vs. ARDS (for TNF $\alpha$ $p<0.001$; for IL-8 and Casp-3 and TBARS $p<0.01$ ). Only the higher dose DEX-1.0 significantly reduced the level of IL-6 $(p<0.05)$ vs. ARDS group (Fig. 2B).

\section{Lung edema and protein content in the BALF}

Formation of the lung edema expressed as a wetdry lung weight ratio (W/D ratio) and protein content in the BALF increased in ARDS group vs. Control (both $p<0.001)$. Both DEX therapies comparably decreased W/D ratio (both $p<0.05$ ) and total protein content (both $p<0.05$ ) vs. ARDS group (Fig. $2 \mathrm{G}, 2 \mathrm{H}$ ).

\section{Discussion}

Considering the early phase of ARDS 
Table 1. Respiratory parameters: mean airway pressure (MAP), dynamic lung-thorax compliance (Cdyn), airway resistance (Raw), partial pressure of carbon dioxide $\left(\mathrm{PaCO}_{2}\right)$, oxygen saturation $\left(\mathrm{SatO}_{2}\right)$, and $\mathrm{pH}$ before (basal value, $\mathrm{BV}$ ) and after induced ARDS (Model) and within $4 \mathrm{~h}$ after administration of the therapy (Th) in Control group, ARDS untreated group, and ARDS groups treated with $0.5 \mathrm{mg} / \mathrm{kg}$ of dexamethasone (DEX-0.5) or $1.0 \mathrm{mg} / \mathrm{kg}$ of dexamethasone (DEX-1.0). Data are presented as means \pm SEM.

\begin{tabular}{|c|c|c|c|c|c|c|c|}
\hline & BV & Model & 30' Th & 1h Th & $2 h \mathrm{Th}$ & 3h Th & 4h Th \\
\hline \multicolumn{8}{|c|}{ MAP (kPa) } \\
\hline Control & $0.77 \pm 0.02$ & $0.74 \pm 0.02$ & $0.73 \pm 0.02$ & $0.73 \pm 0.02$ & $0.71 \pm 0.01$ & $0.71 \pm 0.01$ & $0.73 \pm 0.02$ \\
\hline$A R D S$ & $0.81 \pm 0.03$ & $1.11 \pm 0.03^{\dagger \dagger}$ & $1.08 \pm 0.03^{\dagger \dagger \dagger}$ & $1.07 \pm 0.03^{\dagger \dagger \dagger}$ & $1.13 \pm 0.04^{\dagger \dagger \dagger}$ & $1.14 \pm 0.04^{\dagger \dagger \dagger}$ & $1.14 \pm 0.04^{\dagger \dagger \dagger}$ \\
\hline$D E X-0.5$ & $0.81 \pm 0.01$ & $1.06 \pm 0.04$ & $0.94 \pm 0.04$ & $1.00 \pm 0.03$ & $0.91 \pm 0.03 * *$ & $0.94 \pm 0.06^{* *}$ & $0.97 \pm 0.07 *$ \\
\hline$D E X-1.0$ & $0.79 \pm 0.05$ & $1.07 \pm 0.07$ & $0.97 \pm 0.07$ & $0.97 \pm 0.07$ & $0.91 \pm 0.07 * *$ & $0.97 \pm 0.07 *$ & $1.01 \pm 0.08$ \\
\hline \multicolumn{8}{|c|}{ Cdyn (ml/kPa) } \\
\hline Control & $14.5 \pm 0.58$ & $15.0 \pm 0.38$ & $15.4 \pm 0.57$ & $15.3 \pm 0.47$ & $14.7 \pm 0.68$ & $15.1 \pm 0.40$ & $15.3 \pm 0.64$ \\
\hline$A R D S$ & $13.63 \pm 0.71$ & $7.13 \pm 0.35^{\dagger \dagger}$ & $7.50 \pm 0.38^{\dagger \dagger \dagger}$ & $6.88 \pm 0.40^{\dagger \dagger \dagger}$ & $7.25 \pm 0.41^{\dagger \dagger \dagger}$ & $6.38 \pm 0.38^{\dagger \dagger \dagger}$ & $6.13 \pm 0.40^{\dagger \dagger \dagger}$ \\
\hline$D E X-0.5$ & $13.86 \pm 0.26$ & $8.29 \pm 0.42$ & $8.43 \pm 0.69$ & $8.29 \pm 0.87$ & $9.43 \pm 0.78$ & $8.71 \pm 0.97^{*}$ & $8.43 \pm 0.78^{*}$ \\
\hline$D E X-1.0$ & $13.63 \pm 0.75$ & $8.13 \pm 0.67$ & $8.75 \pm 0.94$ & $8.88 \pm 0.97$ & $8.88 \pm 0.97$ & $8.75 \pm 0.96^{*}$ & $8.75 \pm 0.86^{*}$ \\
\hline \multicolumn{8}{|c|}{$\operatorname{Raw}(\mathrm{kPa} / \mathrm{l} / \mathrm{s})$} \\
\hline Control & $4.39 \pm 0.22$ & $4.41 \pm 0.37$ & $4.84 \pm 0.42$ & $4.56 \pm 0.35$ & $4.97 \pm 0.34$ & $4.61 \pm 0.27$ & $4.44 \pm 0.31$ \\
\hline$A R D S$ & $4.84 \pm 0.53$ & $11.39 \pm 1.92^{\dagger \dagger}$ & $12.91 \pm 2.09^{\dagger \dagger \dagger}$ & $14.57 \pm 2.53^{\dagger \dagger \dagger}$ & $14.39 \pm 2.96^{\dagger \dagger \dagger}$ & $14.07 \pm 2.84^{\dagger \dagger \dagger}$ & $15.02 \pm 3.03^{\dagger \dagger \dagger}$ \\
\hline$D E X-0.5$ & $4.72 \pm 0.29$ & $7.69 \pm 0.65$ & $8.7 \pm 0.84$ & $8.99 \pm 0.69^{*}$ & $7.66 \pm 0.72 * *$ & $8.58 \pm 1.27^{*}$ & $9.07 \pm 1.09^{*}$ \\
\hline$D E X-1.0$ & $4.93 \pm 0.32$ & $9.65 \pm 1.88$ & $8.94 \pm 0.98$ & $8.61 \pm 1.20^{* *}$ & $8.84 \pm 1.30^{*}$ & $8.57 \pm 1.28^{*}$ & $8.89 \pm 1.30 * *$ \\
\hline \multicolumn{8}{|c|}{$\mathrm{PaCO}_{2}(\mathrm{kPa})$} \\
\hline Control & $4.17 \pm 0.27$ & $4.47 \pm 0.27$ & $4.12 \pm 0.24$ & $4.18 \pm 0.30$ & $4.07 \pm 0.32$ & $4.01 \pm 0.28$ & $3.76 \pm 0.31$ \\
\hline$A R D S$ & $3.89 \pm 0.26$ & $6.79 \pm 0.33^{\dagger \dagger \dagger}$ & $6.94 \pm 0.44^{\dagger \dagger \dagger}$ & $6.84 \pm 0.35^{\dagger \dagger \dagger}$ & $6.67 \pm 0.27^{\dagger \dagger \dagger}$ & $6.3 \pm 0.24^{\dagger \dagger \dagger}$ & $6.26 \pm 0.33^{\dagger \dagger \dagger}$ \\
\hline$D E X-0.5$ & $3.99 \pm 0.08$ & $6.5 \pm 0.38$ & $5.97 \pm 0.32$ & $6.17 \pm 0.37$ & $5.86 \pm 0.37$ & $5.94 \pm 0.58$ & $5.7 \pm 0.50$ \\
\hline$D E X-1.0$ & $3.87 \pm 0.25$ & $6.49 \pm 0.27$ & $6.22 \pm 0.25$ & $6.02 \pm 0.30$ & $5.66 \pm 0.32$ & $5.31 \pm 0.37$ & $5.1 \pm 0.36^{*}$ \\
\hline \multicolumn{8}{|c|}{$\mathrm{SatO}_{2}(\%)$} \\
\hline Control & $99.9 \pm 0.00$ & $99.9 \pm 0.00$ & $99.9 \pm 0.00$ & $99.9 \pm 0.00$ & $99.9 \pm 0.00$ & $99.9 \pm 0.00$ & $99.89 \pm 0.01$ \\
\hline$A R D S$ & $99.9 \pm 0.00$ & $96.15 \pm 0.80$ & $95.85 \pm 0.84$ & $90.11 \pm 4.19^{\dagger \dagger \dagger}$ & $90.85 \pm 3.04^{\dagger \dagger \dagger}$ & $93.99 \pm 1.46^{\dagger}$ & $88.39 \pm 5.22^{\dagger \dagger \dagger}$ \\
\hline$D E X-0.5$ & $99.9 \pm 0.00$ & $97.39 \pm 0.65$ & $97.47 \pm 0.72$ & $97.16 \pm 0.94 *$ & $98.76 \pm 0.42 * *$ & $99.2 \pm 0.30$ & $99.49 \pm 0.19 * * *$ \\
\hline$D E X-1.0$ & $99.91 \pm 0.01$ & $95.61 \pm 3.21$ & $98.86 \pm 0.26$ & $98.63 \pm 0.41 * *$ & $99.17 \pm 0.26^{* *}$ & $99.76 \pm 0.05^{*}$ & $99.8 \pm 0.05 * * *$ \\
\hline \multicolumn{8}{|l|}{ pH } \\
\hline Control & $7.47 \pm 0.01$ & $7.42 \pm 0.02$ & $7.41 \pm 0.01$ & $7.37 \pm 0.01$ & $7.31 \pm 0.03$ & $7.28 \pm 0.02$ & $7.26 \pm 0.02$ \\
\hline$A R D S$ & $7.55 \pm 0.01$ & $7.23 \pm 0.02^{\dagger \dagger \dagger}$ & $7.22 \pm 0.02^{\dagger \dagger \dagger}$ & $7.2 \pm 0.03^{\dagger \dagger \dagger}$ & $7.15 \pm 0.02^{\dagger \dagger \dagger}$ & $7.11 \pm 0.03^{\dagger \dagger \dagger}$ & $7.07 \pm 0.02^{\dagger \dagger \dagger}$ \\
\hline$D E X-0.5$ & $7.49 \pm 0.03$ & $7.24 \pm 0.02$ & $7.24 \pm 0.02$ & $7.22 \pm 0.03$ & $7.21 \pm 0.02 *$ & $7.18 \pm 0.03^{*}$ & $7.13 \pm 0.03 *$ \\
\hline$D E X-1.0$ & $7.5 \pm 0.03$ & $7.26 \pm 0.02$ & $7.23 \pm 0.02$ & $7.22 \pm 0.03$ & $7.16 \pm 0.04$ & $7.16 \pm 0.03$ & $7.15 \pm 0.03 *$ \\
\hline
\end{tabular}

characterized by neutrophil-mediated inflammation, lung cell injury and apoptosis with subsequent influx of protein-rich fluid into the alveoli and edema formation, therapy with glucocorticoids (GC) may be of benefit, due to their potent anti-inflammatory and anti-edematous properties (Coutinho and Chapman 2011). Positive effects of GC therapy have been previously shown in various models of lung injury (Wang et al. 2005, Beck et al. 2009, Newton et al. 2010) and their role was found in favor of treatment of ARDS (Peter et al. 2008). There are evidences for the beneficial role of dexamethasone (DEX) in ARDS condition (Villar et al. 2016, Qin and Qiu 2019), particularly for low dose of DEX (Lee et al. 2005, Xinmin et al. 2006, Wang et al. 2008). Controversial results found in the previous studies on the use of GC could arise from the different study designs and etiology of ARDS as well as from different dosage and timing of administration (Ruan et al. 2014). 
Table 2. Total and differential leukocyte count in the arterial blood before (basal value, BV) and in the $4 \mathrm{~h}$ of the therapy (Th); and in the bronchoalveolar lavage fluid (BALF) in Control group, ARDS untreated group, and ARDS groups treated with $0.5 \mathrm{mg} / \mathrm{kg}$ of dexamethasone (DEX-0.5) or $1.0 \mathrm{mg} / \mathrm{kg}$ of dexamethasone (DEX-1.0). Data are presented as means $\pm \mathrm{SEM}$.

\begin{tabular}{|c|c|c|c|c|c|}
\hline \multicolumn{6}{|l|}{ ARTERIAL BLOOD } \\
\hline & & Control & ARDS & DEX-0.5 & DEX-1.0 \\
\hline \multicolumn{6}{|c|}{ Total count of leukocytes $\left(\times 10^{6} / \mathrm{ml}\right)$} \\
\hline & BV & $1.99 \pm 0.37$ & $3.26 \pm 1.05$ & $2.57 \pm 0.57$ & $4.24 \pm 0.57$ \\
\hline & 4h Th & $3.11 \pm 0.81$ & $1.29 \pm 0.25^{\dagger}$ & $1.98 \pm 0.42$ & $1.84 \pm 0.53$ \\
\hline \multicolumn{6}{|l|}{ Differential count $(\%)$} \\
\hline \multirow{2}{*}{ Neutrophils } & BV & $2.54 \pm 0.81$ & $1.84 \pm 0.59$ & $2.04 \pm 0.45$ & $3.53 \pm 0.90$ \\
\hline & $4 \mathrm{~h} T h$ & $51.79 \pm 6.49$ & $21.56 \pm 3.09^{\dagger \dagger}$ & $50.64 \pm 5.90^{*}$ & $44.07 \pm 4.94 *$ \\
\hline \multirow{2}{*}{ Lymphocytes } & BV & $92.91 \pm 1.86$ & $96.27 \pm 0.87$ & $93.5 \pm 2.08$ & $93.48 \pm 1.16$ \\
\hline & 4h Th & $42.1 \pm 5.41$ & $79.87 \pm 2.34^{\dagger \dagger}$ & $47.59 \pm 5.78^{*}$ & $53.74 \pm 4.78 *$ \\
\hline \multirow{2}{*}{ Monocytes } & $\mathrm{BV}$ & $1.3 \pm 0.25$ & $0.93 \pm 0.13$ & $1.18 \pm 0.19$ & $0.98 \pm 0.12$ \\
\hline & 4h Th & $1.2 \pm 0.19$ & $0.77 \pm 0.16^{\dagger}$ & $1.07 \pm 0.20$ & $1.49 \pm 0.22 *$ \\
\hline \multirow{2}{*}{ Eosinophils } & BV & $0.84 \pm 0.27$ & $0.96 \pm 0.39$ & $1.38 \pm 0.50$ & $0.96 \pm 0.19$ \\
\hline & $4 \mathrm{~h} \mathrm{Th}$ & $0.36 \pm 0.12$ & $0.39 \pm 0.17$ & $0.7 \pm 0.18$ & $0.7 \pm 0.23$ \\
\hline \multicolumn{6}{|l|}{ BALF } \\
\hline & & $\mathbf{C}$ & ARDS & DEX-0.5 & DEX-1.0 \\
\hline Total count $\left(\times 10^{3} / \mathrm{ml}\right)$ & & $2.29 \pm 0.29$ & $63.33 \pm 9.67^{\dagger \dagger \dagger}$ & $8.14 \pm 2.40^{*}$ & $3.63 \pm 0.80 * *$ \\
\hline Monocytes (\%) & & $96.51 \pm 1.14$ & $20.43 \pm 4.32^{\dagger \dagger \dagger}$ & $33.6 \pm 10.07$ & $56.1 \pm 6.35^{*}$ \\
\hline Neutrophils (\%) & & $2.74 \pm 0.87$ & $76.67 \pm 4.57^{\dagger \dagger \dagger}$ & $63.5 \pm 9.67$ & $39.87 \pm 5.72 *$ \\
\hline Eosinophils (\%) & & $0.74 \pm 0.28$ & $2.91 \pm 0.72^{\dagger}$ & $2.74 \pm 0.56$ & $2.77 \pm 0.56$ \\
\hline
\end{tabular}

Table 3. Oxidative and inflammatory markers in the plasma: 3-nitrotyrosine (3NT), thiobarbituric acid-reactive substances (TBARS, and cytokines TNFa, IL- 6 and IL-8 in Control group, ARDS untreated group, and ARDS groups treated with $0.5 \mathrm{mg} / \mathrm{kg}$ of dexamethasone (DEX-0.5) or $1.0 \mathrm{mg} / \mathrm{kg}$ of dexamethasone (DEX-1.0). Data are presented as means $\pm \mathrm{SEM}$.

\begin{tabular}{lccccc}
\hline & 3NT & TBARS & TNF $\boldsymbol{\alpha}$ & IL-6 & IL-8 \\
\hline Control & $18.09 \pm 0.3$ & $6.43 \pm 0.8$ & $14.5 \pm 6.8$ & $9.67 \pm 2.1$ & $424.1 \pm 75.1$ \\
ARDS & $21.88 \pm 1.7^{\dagger}$ & $9.97 \pm 1.2^{\dagger}$ & $106.8 \pm 18.6^{\dagger \dagger}$ & $44.97 \pm 8.2^{\dagger \dagger}$ & $1050.0 \pm 116.7^{\dagger \dagger}$ \\
$D E X-0.5$ & $18.3 \pm 0.5^{*}$ & $7.22 \pm 0.3$ & $81.53 \pm 22.3$ & $22.41 \pm 4.6$ & $550.6 \pm 133.8$ \\
$D E X-1.0$ & $18.9 \pm 0.9$ & $6.69 \pm 0.6^{*}$ & $64.45 \pm 24.9^{*}$ & $13.56 \pm 4.3^{*}$ & $634.1 \pm 202.5$ \\
\hline
\end{tabular}

The effective dosage of DEX and action in early stage of developing ARDS is still unresolved and definite conclusion cannot be made. Thus, our study has focused on efficiency of two different low bolus doses of dexamethasone $(0.5$ and $1.0 \mathrm{mg} / \mathrm{kg})$ administered intravenously directly after developing ARDS condition, where anti-inflammatory and anti-edematous activity of DEX was expected to improve finally the lung function in experimental ARDS.

ARDS is associated with a diffuse alveolar epithelial and endothelial damage leading to an influx of fluid and activated inflammatory cells into the alveoli what could negatively affect a surfactant function and thus the respiration (Ranieri et al. 2012). In our study, repeated lung lavage with a saline led to deterioration of the lung function parameters $(\mathrm{P} / \mathrm{F}$ ratio, OI, VEI, AaG, MAP, $\mathrm{C}_{\text {dyn }}$, Raw, $\mathrm{PaCO}_{2}$ ) within minutes after the insult what is consistent with the findings of other authors (Kamiyama et al. 2015, Ricci et al. 2017). Administration of DEX in both doses improved the lung function parameters. However, rapid improvement in $\mathrm{P} / \mathrm{F}$ ratio and oxygenation index was observed within the first $30 \mathrm{~min}$ after administration of the higher dose of DEX-1.0, which persisted till the end of experiment. Significant effect of 

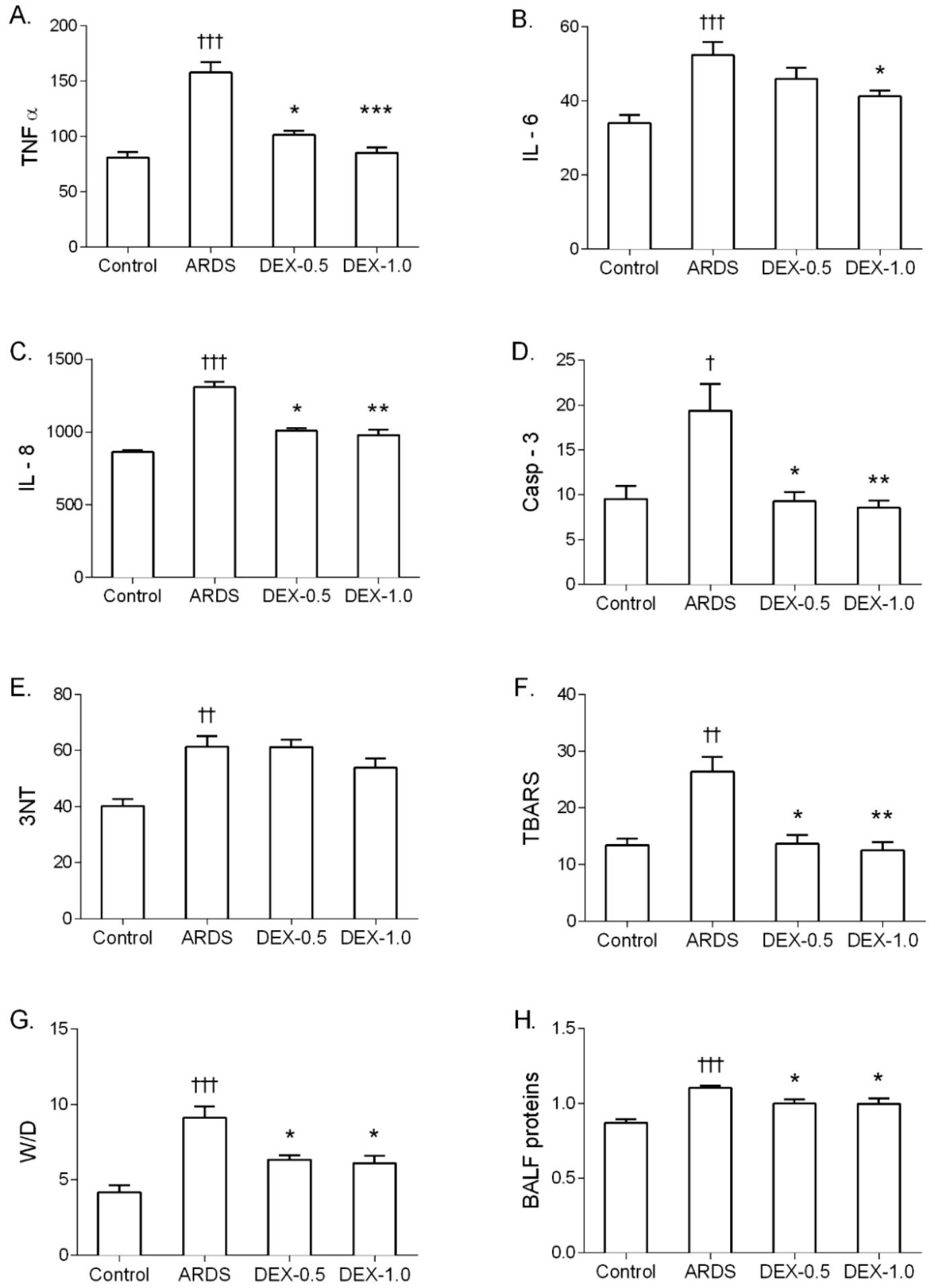

Fig. 2. Levels of cytokines (A) TNFa, (B) IL-6 and (C) IL-8; (D) marker of apoptotic process caspase-3 (Casp-3); (E) protein oxidation (concentration of 3-nitrotyrosine, 3NT) and (F) lipid oxidation (thiobarbituric acid-reactive substances, TBARS); (G) lung edema formation expressed as wet-dry (W/D) lung weight ratio; (H) protein content in bronchoalveolar lavage fluid (BALF) in lung tissue homogenate in Control group, ARDS untreated group, and ARDS groups treated with $0.5 \mathrm{mg} / \mathrm{kg}$ of dexamethasone (DEX-0.5) or $1.0 \mathrm{mg} / \mathrm{kg}$ of dexamethasone (DEX-1.0). Data are presented as means \pm SEM. Statistical comparisons: for ARDS vs. Control ${ }^{\dagger} p<0.05$, ${ }^{+\dagger} p<0.01,{ }^{++} p<0.001$; and for DEX-0.5 \& DEX-1.0 vs. ARDS ${ }^{*} p<0.05,{ }^{* *} p<0.01,{ }^{* * *} p<0.001$.

DEX-1.0 was underlined in $\mathrm{P} / \mathrm{F}$ ratio and alveolar-arterial gradient $(\mathrm{AaG})$ at $3 \mathrm{~h}$ of the therapy compared to lower dose. In addition, only the higher dose of DEX improved VEI compared to ARDS group. Previous studies demonstrated positive effects of GC in experimental (Mokra et al. 2007, Kosutova et al. 2016) and clinical studies (Meduri et al. 2007, Tang et al. 2009). GC could enhance the lung function improving oxygenation and 
ventilatory parameters leading to reduction of period of oxygen dependency and duration of ICU and hospital stay.

The ARDS is associated with influx of leukocytes into the alveolar spaces. We observed a significant increase of total leukocytes count, neutrophils and eosinophils in the BALF in ARDS group compared to controls what is in agreement with other studies (Noda et al. 2003, Waragai et al. 2007, Abdelmageed et al. 2016). Administration of the higher dose of DEX significantly affected the leukocytes in the BALF by decreasing their total count and neutrophils as we observed previously (Mokra et al. 2007, Kosutova et al. 2016).

Subsequent neutrophils activation in the lung leads to inflammation which plays a key role in a progression of ARDS. In our experiments, increased levels of pro-inflammatory cytokines (TNF $\alpha$, IL-6 and IL-8) in the plasma and lung tissue homogenates of ARDS animals were detected, similarly to results of other authors (Kalk et al. 2008, Kamiyama et al. 2015). The inhibitory effects of $\mathrm{GC}$ on the inflammation are partially mediated through an inhibition of the synthesis of NF- $\mathrm{KB}$ dependent pro-inflammatory cytokines (Coutinho and Chapman 2011). In this study, DEX administration decreased levels of pro-inflammatory cytokines in the lung and plasma compared to the ARDS group, while the higher dose DEX-1.0 had slightly stronger impact on these changes. The effectiveness of dexamethasone in reducing levels of cytokines was observed also by other authors (Xinmin et al. 2006, Qin and Qiu 2019).

Overzealous activation of neutrophils could lead to the tissue damage through protein and lipid oxidation (Matthay and Zemans 2011). In our experiments, protein nitrosylation (expressed by 3NT) and lipid peroxidation (expressed by TBARS) significantly increased in the lung and plasma after the lavage-induced lung injury. Neutrophil-induced damage of proteins and lipids through their oxidation was previously published (Lang et al. 2002). Generated ROS have indirect proinflammatory effects and together with inflammation participate in activation of caspase-3, which causes the direct epithelial injury via apoptotic pathways (Galani et al. 2010). An increased level of caspase-3 in the ARDS animals in our study indicates an activation of proapoptotic processes early after the triggering injury. DEX of both dosages decreased the markers of oxidative damage in the plasma, while TBARS and caspase- 3 significantly decreased also in the lung tissue. Similarly to our results, dexamethasone alleviated inflammation and suppressed Fas ligand and thus extrinsic apoptotic pathway in other experimental ARDS model (Beck et al. 2009) and inhibited an activation of caspase- 3 and -7 in the lung epithelial cells (Wen et al. 1997).

The inflammatory mediators and bioactive substances including ROS damage the endothelial and epithelial cells and thereby increase the permeability across the alveolar-capillary membrane, resulting in the pulmonary edema formation (Matthay and Zemans 2011). In this study, Degree of the lung edema formation calculated as a ratio of wet and dry lung weight (W/D) and estimated also using total protein content in BALF significantly increased in the ARDS group, similarly to other authors (Li et al. 2016). Both dosages of DEX significantly decreased the lung edema formation and the protein content in the BALF compared to untreated animals.

Nevertheless, our findings are in conflict with another very similar study, where systemic dexamethasone did not have any effect on clinic parameters and lung injury (Engel et al. 2015). The discrepancy may be related to different experimental animals used in these studies and varied lung lavage and treatment protocol. On the other hand, other several studies showed positive effect of low-dose steroids on early phase ARDS (Annane et al. 2006, Meduri et al. 2007, Meduri et al. 2008, Wang et al. 2008, Tang et al. 2009). Taken together, dexamethasone can be of benefit in the therapy of ARDS. Both low doses of DEX could prevent migration of polymorphonuclear leukocytes into the lung and modulate their activation what could inhibit the local inflammation and alleviate respiratory failure.

In this study, the higher dose of DEX $(1.0 \mathrm{mg} / \mathrm{kg})$ showed more obvious improvement in the parameters of oxygenation and VEI with faster onset of the action than the lower dose of DEX $(0.5 \mathrm{mg} / \mathrm{kg})$ in the early phase ARDS, however, this effect was only temporary. Therefore, we can speculate that the use of lower dose of DEX $(0.5 \mathrm{mg} / \mathrm{kg})$ can be considered for more reasonable as it provides nearly comparable effects on the lung function, inflammation, oxidation and lung edema formation to higher dose of DEX $(1 \mathrm{mg} / \mathrm{kg})$, but in expected lower risk of occurrence of the side effects, whereas the development of side effects of GC is timeand dose-dependent. Even though the early and low-dose dexamethasone during early phase ARDS had positive effect consistent with a meta-analysis of recent randomized controlled trials (Yang et al. 2017), further research in this field is necessary. 


\section{Declaration of Interests}

The authors report no conflicts of interest. The authors alone are responsible for the content and writing of the paper.

\section{Conflict of Interest}

There is no conflict of interest.

\section{Acknowledgements}

The authors thank M. Petraskova, M. Hutko, D. Kuliskova and Z. Remisova for technical assistance. The study was supported by projects APVV-15-0075, VEGA 1/0356/18, and the projects "Biomedical Center Martin" (ITMS code 26220220187) and Center of Experimental and Clinical Respirology (CEKRII, ITMS code 26220120034) both co-financed from EU sources.

\section{References}

ABDELMAGEED ME, EL-AWADY MS, ABDELRAHIM M, SUDDEK GM: LPS-RS attenuation of lipopolysaccharide-induced acute lung injury involves NF-kappaB inhibition. Can J Physiol Pharmacol 94: 140-146, 2016.

ANNANE D, SEBILLE V, BELLISSANT E: Effect of low doses of corticosteroids in septic shock patients with or without early acute respiratory distress syndrome. Crit Care Med 34: 22-30, 2006.

BECK JM, PRESTON AM, WILCOXEN SE, MORRIS SB, STURROCK A, PAINE R 3RD: Critical roles of inflammation and apoptosis in improved survival in a model of hyperoxia-induced acute lung injury in Pneumocystis murina-infected mice. Infect Immun 77: 1053-1060, 2009.

CEPKOVA M, MATTHAY MA: Pharmacotherapy of acute lung injury and the acute respiratory distress syndrome. J Intensive Care Med 21: 119-143, 2006.

COUTINHO AE, CHAPMAN KE: The anti-inflammatory and immunosuppressive effects of glucocorticoids, recent developments and mechanistic insights. Mol Cell Endocrinol 335: 2-13, 2011.

CZOCK D, KELLER F, RASCHE FM, HAUSSLER U: Pharmacokinetics and pharmacodynamics of systemically administered glucocorticoids. Clin Pharmacokinet 44: 61-98, 2005.

ENGEL M, NOWACKI RM, BODEN P, REISS LK, UHLIG S, REYNAERT NL, GOPAL P, WOUTERS EF, WILLEMS CH, KLOOSTERBOER N, WOLFS TG, ZIMMERMANN LJ, VOS GD, KRAMER BW: The effects of dexamethasone and oxygen in ventilated adult sheep with early phase acute respiratory distress syndrome. Lung 193: 97-103, 2015.

GALANI V, TATSAKI E, BAI M, KITSOULIS P, LEKKA M, NAKOS G, KANAVAROS P: The role of apoptosis in the pathophysiology of Acute Respiratory Distress Syndrome (ARDS): an up-to-date cell-specific review. Pathol Res Pract 206: 145-150, 2010.

KALK P, SENF P, DEJA M, PETERSEN B, BUSCH T, BAUER C, BOEMKE W, KAISERS U, HOCHER B: Inhalation of an endothelin receptor A antagonist attenuates pulmonary inflammation in experimental acute lung injury. Can J Physiol Pharmacol 86: 511-515, 2008.

KAMIYAMA J, JESMIN S, SAKURAMOTO H, SHIMOJYO N, ISLAM M, HAGIYA K, SUGANO M, UNOKI T, OKI M, KAWANO S, MIZUTANI T: Hyperinflation deteriorates arterial oxygenation and lung injury in a rabbit model of ARDS with repeated open endotracheal suctioning. BMC Anesthesiol 15: 73, 2015.

KOSUTOVA P, MIKOLKA P, BALENTOVA S, ADAMKOV M, KOLOMAZNIK M, CALKOVSKA A, MOKRA D: Intravenous dexamethasone attenuated inflammation and influenced apoptosis of lung cells in an experimental model of acute lung injury. Physiol Res 65 (Suppl 5): S663-S672, 2016.

KOSUTOVA P, MIKOLKA P, KOLOMAZNIK M, REZAKOVA S, CALKOVSKA A, MOKRA D: Effects of roflumilast, a phosphodiesterase-4 inhibitor, on the lung functions in a saline lavage-induced model of acute lung injury. Physiol Res 66 (Suppl 2): S237-S245, 2017.

LANG JD, MCARDLE PJ, O'REILLY PJ, MATALON S: Oxidant-antioxidant balance in acute lung injury. Chest 122: 314S-320S, 2002.

LEE HS, LEE JM, KIM MS, KIM HY, HWANGBO B, ZO JI: Low-dose steroid therapy at an early phase of postoperative acute respiratory distress syndrome. Ann Thorac Surg 79: 405-410, 2005. 
LI G, ZHOU CL, ZHOU QS, ZOU HD: Galantamine protects against lipopolysaccharide-induced acute lung injury in rats. Braz J Med Biol Res 49: e5008, 2016.

MATTHAY MA, ZEMANS RL: The acute respiratory distress syndrome: pathogenesis and treatment. Annu Rev Pathol 6: 147-163, 2011.

MEDURI GU, GOLDEN E, FREIRE AX, TAYLOR E, ZAMAN M, CARSON SJ, GIBSON M, UMBERGER R: Methylprednisolone infusion in early severe ARDS: results of a randomized controlled trial. Chest 131: 954-963, 2007.

MEDURI GU, MARIK PE, CHROUSOS GP, PASTORES SM, ARLT W, BEISHUIZEN A, BOKHARI F, ZALOGA G, ANNANE D: Steroid treatment in ARDS: a critical appraisal of the ARDS network trial and the recent literature. Intensive Care Med 34: 61-69, 2008.

MOKRA D, MOKRY J, DRGOVA A, BUlikOVA J, PETRASKOVA M, CALKOVSKA A: Single-dose versus two-dose dexamethasone effects on lung inflammation and airway reactivity in meconium-instilled rabbits. J Physiol Pharmacol 58 (Suppl 5): 379-387, 2007.

NARUTE P, SEAM N, TROPEA M, LOGUN C, CAI R, SUN J, SHELHAMER JH, MEDURI GU, SUFFREDINI AF: Temporal changes in microrna expression in blood leukocytes from patients with the acute respiratory distress syndrome. Shock 47: 688-695, 2017.

NEWTON R, LEIGH R, GIEMBYCZ MA: Pharmacological strategies for improving the efficacy and therapeutic ratio of glucocorticoids in inflammatory lung diseases. Pharmacol Ther 125: 286-327, 2010.

NODA E, HOSHINA H, WATANABE H, KAWANO T: Production of TNF-alpha by polymorphonuclear leukocytes during mechanical ventilation in the surfactant-depleted rabbit lung. Pediatr Pulmonol 36: 475-481, 2003.

PETER JV, JOHN P, GRAHAM PL, MORAN JL, GEORGE IA, BERSTEN A: Corticosteroids in the prevention and treatment of acute respiratory distress syndrome (ARDS) in adults: meta-analysis. BMJ 336: 1006-1009, 2008.

PIERRAKOS C, KARANIKOLAS M, SCOLLETTA S, KARAMOUZOS V, VELISSARIS D: Acute respiratory distress syndrome: pathophysiology and therapeutic options. J Clin Med Res 4: 7-16, 2012.

QIN M, QIU Z: Changes in TNF-alpha, IL-6, IL-10 and VEGF in rats with ARDS and the effects of dexamethasone. Exp Ther Med 17: 383-387, 2019.

RANIERI VM, RUBENFELD GD, THOMPSON BT, FERGUSON ND, CALDWELL E, FAN E, CAMPOROTA L, SLUTSKY AS: Acute respiratory distress syndrome: the Berlin Definition. JAMA 307: 2526-2533, 2012.

RICCI F, CATOZZI C, MURGIA X, ROSA B, AMIDANI D, LORENZINI L, BIANCO F, RIVETTI C, CATINELLA S, Villetti G, CIVElli M, PIOSElli B, DANI C, SAlOMONE F: Physiological, biochemical, and biophysical characterization of the lung-lavaged spontaneously-breathing rabbit as a model for respiratory distress syndrome. PLoS One 12: e0169190, 2017.

RUAN SY, LIN HH, HUANG CT, KUO PH, WU HD, YU CJ: Exploring the heterogeneity of effects of corticosteroids on acute respiratory distress syndrome: a systematic review and meta-analysis. Crit Care 18: R63, 2014.

TANG BM, CRAIG JC, ESLICK GD, SEPPELT I, MCLEAN AS: Use of corticosteroids in acute lung injury and acute respiratory distress syndrome: a systematic review and meta-analysis. Crit Care Med 37: 1594-1603, 2009.

VERBRUGGE SJ, SORM V, LACHMANN B: Mechanisms of acute respiratory distress syndrome: role of surfactant changes and mechanical ventilation. J Physiol Pharmacol 48: 537-557, 1997.

VILLAR J, BELDA J, ANON JM, BLANCO J, PEREZ-MENDEZ L, FERRANDO C, MARTINEZ D, SOLER JA, AMBROS A, MUNOZ T, RIVAS R, CORPAS R, DIAZ-DOMINGUEZ FJ, SORO M, GARCIA-BELLO MA, FERNANDEZ RL, KACMAREK RM: Evaluating the efficacy of dexamethasone in the treatment of patients with persistent acute respiratory distress syndrome: study protocol for a randomized controlled trial. Trials 17: 342, 2016.

VILLAR J, SULEMANJI D, KACMAREK RM: The acute respiratory distress syndrome: incidence and mortality, has it changed? Curr Opin Crit Care 20: 3-9, 2014.

WANG J, WINSKOG C, EDSTON E, WALTHER SM: Inhaled and intravenous corticosteroids both attenuate chlorine gas-induced lung injury in pigs. Acta Anaesthesiol Scand 49: 183-190, 2005.

WANG XQ, ZHOU X, ZHOU Y, RONG L, GAO L, XU W: Low-dose dexamethasone alleviates lipopolysaccharideinduced acute lung injury in rats and upregulates pulmonary glucocorticoid receptors. Respirology 13: 772-780, 2008. 
WARAGAI A, YAMASHITA H, HOSOI K, HOSHINA H, NODA E, YAN K, KAWANO T: High-frequency oscillation (HFO) prevents activation of NF-kappaB found with conventional mechanical ventilation (CMV) in surfactant-depleted rabbit lung. Pediatr Pulmonol 42: 440-445, 2007.

WEN LP, MADANI K, FAHRNI JA, DUNCAN SR, ROSEN GD: Dexamethasone inhibits lung epithelial cell apoptosis induced by IFN-gamma and Fas. Am J Physiol 273: L921-L929, 1997.

XINMIN D, YUNYOU D, CHAOSHENG P, HUASONG F, PINGKUN Z, JIGUANG M, ZHIQIAN X, QINZHI X: Dexamethasone treatment attenuates early seawater instillation-induced acute lung injury in rabbits. Pharmacol Res 53: 372-379, 2006.

YANG ZG, LEI XL, LI XL: Early application of low-dose glucocorticoid improves acute respiratory distress syndrome: A meta-analysis of randomized controlled trials. Exp Ther Med 13: 1215-1224, 2017.

ZEMANS RL, COLGAN SP, DOWNEY GP: Transepithelial migration of neutrophils: mechanisms and implications for acute lung injury. Am J Respir Cell Mol Biol 40: 519-535, 2009. 